\title{
As contribuições do estágio supervisionado para a constituição da profissionalidade docente
}

\author{
Denise Filomena Bagne Marquesin* \\ Laurizete Ferragut Passos
}

\begin{abstract}
Resumo
Este artigo é um recorte de pesquisa de doutorado e traz como discussão o papel do estágio supervisionado como espaço privilegiado no processo de formação inicial e de constituição da profissionalidade docente de futuras professoras. As contribuições de Montero (2001), Goodson (2008) e Shulman (1987) sobre conhecimentos profissionais e profissionalidade docente, bem como as contribuições de Passeggi (2010) sobre o papel das narrativas na formação indicaram que os significados e as conquistas alcançadas durante a participação no estágio fazem parte da compreensão sobre os conhecimentos necessários para o exercício da docência. O artigo traz as análises das narrativas de cinco alunas do curso de Pedagogia decorrentes do estágio junto às professoras das séries iniciais nas aulas de matemática. O compartilhamento das narrativas evidenciou o potencial formativo dos estágios associado a sua possibilidade de afetar o processo de constituição da profissionalidade docente dos futuros professores.
\end{abstract}

Palavras-chave: Profissionalidade docente; Conhecimentos Profissionais; Formação Inicial; Narrativas.

\section{The supervised the contributions to the professionalism of a teacher}

\begin{abstract}
This article is an excerpt of a $\mathrm{PhD}$ research and discussion brings to the role of supervised internship as a privileged space in the initial formation and constitution of professional teaching future teachers process. The contributions of Montero (2001), Goodson (2008) and Shulman (1987) on teacher professionalism and professional knowledge as well as the contributions of Passegi (2010) on the role of narrative in the formation indicated that the meanings and achievements during participation in the internship are part of the understanding of the knowledge required for the practice of teaching. The article presents the analysis of the narratives of five students from the Pedagogy arising from the stage to the teachers of the lower grades in math classes. The sharing of narratives highlighted the potential of formative stages associated with its ability to affect the process of constitution of professional teaching future teachers.

Keywords: Teaching Professionalism; Professional knowledge; Initial Training; Narratives
\end{abstract}

\section{Introdução}

As pesquisas sobre formação inicial de professores têm indicado a importância de se voltar o olhar para esse período, pois é nele que se criam as bases sobre as quais o futuro professor vai adquirir condições de exercer sua atividade docente, bem como as bases de sua profissionalidade e de constituição da sua profissionalização.

Embora a temática da formação dos professores seja a mais pesquisada no campo da educação, pouco se tem investigado sobre as conexões entre os componentes dos currículos acadêmicos dessa formação e a formação docente que acontece nas escolas (Gatti, Barreto e André, 2011). Ou seja, embora já contemos com as diretrizes nacionais para a formação e com destaque para a questão da relação teoria e prática como fundamental no processo de aprender a ser professor, os currículos dos cursos que formam professores para a escola básica ainda apresentam forte carga teórica e se distanciam dos conhecimentos que podem ser adquiridos das experiências de trabalho nas escolas. Como assinala Silva Júnior (2010), isso acaba sendo uma preparação individual para $\mathrm{o}$ trabalho e não responde às necessidades de reconversão profissional que a contemporaneidade coloca. (p. 7).

Ao reconhecer o valor formativo dos contextos de trabalho, o pesquisador defende que, além da formação acadêmica, a formação inicial de professores "requer uma permanente mobilização dos saberes adquiridos em situações de trabalho, que se constituirão em subsídios para situações de formação, e dessas para novas situações de trabalho". (2010, p. 7).

Tomando como referência essas preocupações com o processo de formação dos professores, o artigo pretende analisar as contribuições do estágio supervisionado para a 
aprendizagem da docência e constituição da profissionalidade docente. Os dados aqui trazidos se referem à análise de narrativas de um grupo de alunas estagiárias do curso de Pedagogia e que têm como foco de trabalho o ensino de matemática para as séries iniciais do ensino fundamental. Esse recorte da pesquisa se justifica pela forma como as narrativas foram produzidas após as atividades desenvolvidas pelas estagiárias e sua reflexão em grupo com a pesquisadora. Dos encontros de reflexão, a pesquisadora produzia, também, sua própria narrativa que expressava seu processo analítico decorrente das reflexões com o grupo de estagiárias.

Sabe-se que a profissão docente está em constante processo de transformação e ressignificação dos conhecimentos profissionais, o que permite evidenciar que a constituição da profissionalidade não se esgota num único momento de realização do estágio; ela se amplia na medida em que o docente ou o futuro docente compreendem que a organização da prática pedagógica envolve um processo dinâmico que abarca a (re)elaboração do saber aprendido, concomitantemente às vivências sociais e profissionais que cada um constrói em seu dia a dia e em torno de sua história. Reconhecer na construção das narrativas indícios desse processo de transformação e ressignificação dos conhecimentos profissionais se constituiu no caminho perseguido pela pesquisa.

\section{As bases do conhecimento para ensinar: a aprendizagem da docência}

Os estudos de Mizukami (2004) trazem as ideias de Shulman (1987) para o centro das discussões sobre os conhecimentos de que o professor necessita para ensinar e para que seu ensino resulte em aprendizagem. Shulman, inicialmente, propôs três categorias de conhecimentos relacionados ao conteúdo: conhecimento da matéria, conhecimento curricular do conteúdo e o conhecimento pedagógico do conteúdo, sendo que o conhecimento dos conteúdos específicos da matéria inclui compreender fatos, conceitos, processos e procedimentos que devem ser articulados com as formas de comunicação, para propiciar a apropriação do conhecimento pelos alunos. Já o conhecimento curricular inclui o conhecimento dos recursos disponíveis para estruturar uma determinada matéria para o ensino e para o cumprimento do programa previsto. O conhecimento pedagógico do conteúdo transcende uma área específica, inclui teorias e princípios relacionados ao ensinar e ao aprender, é construído constantemente pelo professor, ao ensinar a matéria, e pode ser considerado como um novo tipo de conhecimento, pois é enriquecido por representações, analogias, exemplos, demonstrações, que se incluem nas concepções ou pré-concepções que os alunos trazem para as situações de aprendizagem.

Outro autor que contribuiu para os estudos teóricos sobre os conhecimentos profissionais dos professore é Moura (2001) que, ao indagar sobre a complexidade ação de ensinar, define como elemento-chave da profissão docente o estabelecimento de condições criativas para que as experiências docentes desenhem aprendizagens ascendentes e de conquista. $\mathrm{O}$ papel do professor como profissão envolve

compromisso político, ética profissional, conhecimento do conteúdo e do currículo que deverá desenvolver, conhecimento didático, participação na vida escolar e se perceber como aprendiz permanente (desenvolvimento profissional). (MOURA, 2001, p.129)

Os conhecimentos profissionais docentes, nesse sentido, envolvem as vivências e as experiências, os acontecimentos como recursos discursivos, os saberes docentes, os conteúdos sobre o ensinar, as condições e as possibilidades de aprendizagem profissional durante a formação inicial e durante a carreira.

Goodson (2008) considera que o percurso profissional sempre é marcado pela mobilização de conhecimentos já existentes e pela produção de novos, e isso exige que o próprio professor vincule sua formação docente à sua profissionalização. $\mathrm{O}$ pesquisador apresenta a distinção entre profissionalização e profissionalismo: caracteriza como profissionalização o investimento num projeto que envolve a busca de status e de recursos para um grupo profissional e afirma ser o profissionalismo o outro lado da moeda, pois se direciona à prática e à profissão de ensinar, ou seja, "à definição que os professores fazem das práticas do seu grupo de pares e das formas que concretizarem a arte e o ofício de ensinar" (GOODSON, 2008, p. 210).

Assim, a atividade docente demanda um tempo de apropriação de conhecimentos que está diretamente vinculado à articulação e à mobilização de saberes contextualizados - do conteúdo, das práticas curriculares, teóricos e da ação pedagógica. Nesse conjunto de características que compõem a 
racionalização dos conhecimentos e das habilidades necessárias ao exercício da atividade docente podese identificar a constituição da profissionalidade docente. Defende-se, assim, que a formação inicial dos professores, de forma geral, e o estágio supervisionado, de forma particular, devem afetar o processo de constituição da profissionalidade e profissionalização dos docentes em formação.

\section{O estágio supervisionado como objeto de estudo e o contexto da pesquisa}

Estudos e discussões sobre a legislação vigente e sobre os objetivos e as contribuições do estágio supervisionado levam a conceber que, ao adentrar na sala de aula, o aluno da formação inicial tem, pela primeira vez, a oportunidade de fazer a leitura da profissão docente não mais na condição de aluno, e sim como aprendiz da profissão. Dessa forma, concebe-se que o estágio é um momento especial do processo de formação do professor, em que ocorrem, de maneira mais efetiva, a transição e a passagem de aluno a professor.

Cochran-Smith e Lytle (1999) utilizam a metáfora "dentro/fora" para representar a imagem ambígua que simboliza o futuro professor quando está na condição de aprendiz da profissão e frequenta o ambiente de sala de aula. Ora ele fica perplexo com a situação, que envolve aspectos de ensino e de aprendizagem, aspectos afetivos de comportamento do aluno e do professor e uma ou outra vez ele faz relação com as questões históricas, econômicas e sociais e afirma não adotar tal procedimento ou postura; ora fica em dúvida se teria conhecimento suficiente para ensinar e oferecer oportunidades para aprendizagem ou resolver o conflito instaurado durante a aula; ora, ainda, considera que ser professor é reproduzir o que vivenciou como aluno.

Para Sanmamed e Abeledo (2011), o aluno estagiário, ao interagir com o ambiente físico, social e educacional, precisa ser encorajado a desenvolver por si seu próprio conhecimento, agindo de forma reflexiva diante das inúmeras situações do cotidiano escolar, já que, normalmente, ele visualiza os professores das classes como o "conhecedor do conhecido", que tem status de manejar as situações da classe e que domina todo o conhecimento para ensinar. O estágio "é um fator chave no processo educacional e para o aluno em formação, é uma oportunidade única de aprender a profissão docente sem ter a enorme responsabilidade que ela exige ",l ( p. 48).

Pimenta (2001) faz críticas ao estágio concebido como um período limitado do tempo em que o aluno em formação é obrigado a cumprir uma carga horária e frequentar ambiente escolar, cuja atividade não faz parte integralmente da realidade da qual ele se aproxima. Esse tempo de obrigação se restringe, muitas vezes, à frequência e à produção de relatórios para cumprimento das exigências legais propostas pela disciplina.

Em outro artigo, Pimenta e Lima (2004) enfatizam que a aproximação da realidade desenvolvida pelo estagiário, no caso do estágio cumprido por obrigação sem articulação com a formação oferecida no curso superior, assemelha-se ao "olhar de estrangeiro", ou seja, de alguém que está de fora, que veio de um outro contexto, que não está condicionado ao cotidiano daquela prática.

A frequência e a participação do aluno da licenciatura dentro da escola, durante a realização do estágio, permitem-lhe verificar que a prática do professor para ensinar é complexa e singular e, até mesmo, incerta, por vezes, exigindo do professor a busca intencional do diálogo entre os saberes da prática, para construção do conhecimento profissional sobre ensinar (MOURA, 2001).

Essas considerações demandaram um processo de coleta de dados mais ampliado durante a realização da pesquisa. Outros instrumentos foram utilizados como questionários para os 46 alunos do curso de Pedagogia; entrevista exploratória com um grupo de 5 alunas que optaram por realizar o estágio na escola de Ensino Fundamental que aceitou fazer parte da pesquisa; e, na fase final de pesquisa, um grupo de discussão com 12 alunos desse curso, incluindo as 5 alunas que se tornaram sujeitos da pesquisa. A participação na pesquisa articulou-se com a proposta de produção de narrativas pelas alunas e pela pesquisadora, para leitura e reflexão nos encontros quinzenais com a pesquisadora, nas dependências da instituição de Ensino Superior.

\section{As narrativas: o processo de construção, as percepções iniciais as contribuições para constituição da profissionalidade docente}

As narrativas sobre as vivências no estágio e os elementos de discussão durante suas leituras pautaram-se nos registros sobre o contato das alunas estagiárias com a professora da classe e das estagiárias com os alunos. Essas vivências foram determinantes para que suas memórias e lembranças (re)significassem suas concepções sobre ensinar e aprender, recuperassem suas visões de escola e oportunizassem uma nova concepção da profissão.

A construção das narrativas era individual e 
acontecia logo após a participação no estágio realizado na escola municipal. As alunas do curso de Pedagogia dispunham de um caderno, e seus registros pessoais serviam de suporte para a produção das narrativas. Esse caderno ficava à disposição da pesquisadora e da professora titular da classe e dava transparência ao processo de pesquisa.

É importante destacar que a relação das professoras titulares com as alunas estagiárias inicialmente era de desconfiança, porém, a partir do momento em que as alunas começaram a deixar seus registros à disposição das professoras e da diretora, essa relação foi se alterando e tornando-se mais próxima, já que os registros eram fiéis ao que ocorria na escola.

Como ressalta Bruner (1997), as narrativas são versões da realidade, orientadas, por convenção e necessidade, para o relato de histórias e fatos considerados verdadeiros ou falsos. A defesa e a apresentação do que é narrado depende da intenção do narrador.

Passeggi (2010), corroborando a ampliação da compreensão sobre a narrativa como versão da realidade, mostra que a narrativa, quando adotada como instrumento de pesquisa, exige uma análise multirreferencial inserida na perspectiva do interacionismo sociodiscursivo, pois é um gênero textual em que o processo de autoria e o de construção identitária se entrelaçam: o narrador coincide, enquanto escreve, com o autor empírico do texto. Ele é o agente responsável pela totalidade das operações do ato de escrever. Assim, o processo de escrita consiste na apropriação de novos saberes conceituais, sobre a língua e sobre o conteúdo que narra, transformadores dos conhecimentos sobre suas práticas pedagógicas, de escrita e sociais. A escrita, também, transforma um conhecimento de senso comum em acadêmico, na medida em que ressignifica, examina e retoma suas palavras para apresentar suas ações, suas crenças e seus valores. Para a autora, a liberdade do narrador de controlar, censurar e aprovar o que escreve provoca mudanças na constituição identitária, o que lhe permite apropriar-se das representações de si mesmo.

As narrativas, nesse sentido, demonstraram ser excelentes recursos para que as alunas estagiárias comunicassem suas vivências, suas impressões e seus conhecimentos. A análise de cada texto implicava não apenas a exploração do que estava escrito, mas também a análise do modo figurativo da linguagem.

A narrativa da aluna Marta sobre as contribuições do estágio traz de modo figurativo a percepção dos significados que atribui para o estágio: foi a partir do estágio que ela concluiu que tinha escolhido a profissão certa.

Para mim, o estágio está sendo um espelho do que vou encontrar na profissão. Eu percebi que mudou muito o ambiente de sala de aula em relação à época que fui aluna de $1^{\circ}$ ao $4^{\circ}$ ano. Eu fico um dia com uma professora e outro com outra professora. Eu consigo analisar os procedimentos de cada professora para dar aula e para atender os alunos. Enquanto uma professora é mais dinâmica, explica bem e atende os alunos, outra professora é mais preocupada com a rotina e com o tempo de cada atividade. Reflito sobre cada situação, vejo o quanto é difícil ter que decidir sobre o que deve ser feito e o que deve ser seguido, reflito sobre as situações e faço um ensaio: se eu fosse a professora, faria dessa forma. Penso que o estágio é uma oportunidade de fazer este ensaio de como eu faria para conseguir que todas as crianças aprendam. Enfim, por isso considero que estágio é um espelho. $(\text { MARTA, n.12, } 28 \text { ago. 2010 })^{2}$

As alunas estagiárias, mesmo tendo sido informadas de que $\mathrm{o}$ foco da pesquisa estava direcionado para o ensino dos conteúdos de matemática nos anos iniciais, sentiram necessidade de discutir outros aspectos que observaram no cotidiano escolar, uma vez que ficavam cinco horas na sala de aula. Essa era a riqueza do processo de apropriação da docência que resultava das indagações que emergiam. Marta, por exemplo, viuse cúmplice da situação real e registrou que entendia a postura da professora. Deixou implícito que concordava com a autoridade da professora, em diferentes momentos, para conseguir a atenção dos alunos. Contudo, no encontro com a pesquisadora, ao ser questionada a respeito da situação narrada, Marta concordou que existe algo que não é coerente com a concepção de ensino que defende o aluno como protagonista da aprendizagem e o professor como mediador da aprendizagem e cujas intervenções precisam ser desafiadoras. Declarou não ter resposta sobre como fazer com que aqueles alunos se sintam desafiados e percebam que os conteúdos da escola e a proposta da professora ajudarão na sua formação; por vezes ficava em dúvida se a postura da professora era a mais aceitável, pois os alunos só realizam a atividade por se sentirem obrigados, mas afirmava que não 
saberia como agir diante aquele dilema.

A reflexão foi produtiva, não havia a intenção de prescrever o que é correto nem o que deveria ser feito; procurava-se, ao contrário, adotar uma postura cuidadosa para as interpretações da prática educativa, pautadas num olhar mais direcionado à apropriação de conhecimentos profissionais para legitimar o processo de profissionalização individualmente e coletivamente.

Letícia, na narrativa abaixo, também expõe suas dúvidas e dilemas diante uma realidade escolar complexa, como a que presenciava no estágio:

Nesta escola vejo que o dia-a-dia é muito difícil. As salas são grandes e serve de biblioteca, palco de teatro, ambiente de estudo. Sinto que somente com a presença mais firme e exigente da professora os alunos são obedientes. Contudo, vejo algumas possibilidades de trabalho diversificado dentro deste precioso ambiente - sala de aula - para esta escola que tem poucos recursos físicos adequados para as crianças. Considero que as crianças precisam ser estimuladas para o conteúdo que será apresentado e, em algumas vezes, poderiam decidir como poderiam realizar as tarefas. O uso do caderno, lápis e lousa para copiar a atividade é cansativo. (LETÍCIA, $4^{\circ}$ ano do EF, narrativa n. 10, 02 abr. 2010)

Assim, no contexto dessas narrativas e de outras não apresentadas, as descobertas das incompreensões e de caminhos ainda não trilhados ficaram evidentes, e os espaços que inicialmente eram narrados com certa naturalidade agora se transformavam em lugares de formação, pois o sentido e o significado das experiências eram apresentados com cumplicidade nas narrativas.

Havia a certeza da criticidade em relação à complexidade de ser professor, decorrente da necessidade de romper com a racionalidade ainda presente na escola hoje, seja na relação de poder da professora com o conteúdo selecionado ou da sua autoridade para garantir o ensino.

Nesse contexto, o espaço, o estágio e os conhecimentos matemáticos ficavam imbricados e traziam, tanto para as alunas como para a pesquisadora, indagações que exigiam pesquisa, discussão e ressignificação.

Esta estrutura foi se ampliando à medida que as leituras aconteciam nos encontros, constituídos também de narrativa orais, resultantes das indagações sobre os detalhes que envolviam a cena, os procedimentos adotados e os que poderiam ser empregados e sobre as percepções do momento.

Assim, o acompanhamento do estágio, pela pesquisadora e pelas alunas, acontecia de forma significativa e transformadora dos conhecimentos profissionais: tanto aqueles conquistados durante a realização do curso de Pedagogia quanto os que foram adquiridos mediante as reflexões críticas nos encontros com a pesquisadora ou durante as vivências na escola de Ensino Fundamental.

Para Passeggi (2010), os vínculos que se entretecem entre a linguagem selecionada, a reflexividade biográfica e a consciência histórica, para produzir a narrativa, têm como princípio a dimensão autopoiética focalizada nas práticas pedagógicas que favorecem a reflexão sobre a ressignificação da experiência no contexto da formação. Referindo-se a Larrosa, a autora enfatiza que "somos a narrativa aberta e contingente das histórias de nossas vidas, a história de quem somos em relação ao que nos acontece" (PASSEGI, 2010, p.147).

Sinto que o estágio, não só para mim, mas para todos, é um momento único. A escola tem vida, gosto muito de participar de tudo: roda de leitura, merenda, montar os cantos para estudos, ensaio de danças para as festas e comemorações. Nunca imaginei que fazer estágio era tão bom. Estamos ficando mais questionadoras. (ANA CLARA).

Nas suas narrativas, Ana Clara normalmente faz críticas aos procedimentos dos professores que não permitem que as crianças apresentem suas opiniões. Compreende que o professor deve ter perfil de líder, mas não concorda com o autoritarismo. Realizou grande parte do estágio numa única classe. Optou por produzir as narrativas somente das aulas de Matemática e analisa com veemência a postura da professora em relação à gestão da sala na hora da explicação dos exercícios:

Hoje prefiro registrar que a professora $D-1$ deve estar com algum problema. As crianças não podem nem se mexer do lugar que ela altera a voz. Para explicar como deveriam copiar e resolver a situação problema da p.46, fez três paradas e pediu silêncio, ameaçando não explicar mais. Algumas crianças apenas copiaram do livro $e$, posteriormente, anotaram o resultado colocado na lousa, ainda bem que após o 
recreio os alunos terão aula de Língua Inglesa seguida da aula de Educação Física ministradas por outros docentes. Fico muitas vezes abismada com a postura autoritária do professor que ainda permanece no final dessa primeira década do século XXI. (ANA CLARA).

A narrativa de Larissa, com o título "Observação da relação aluno e aluno e aluno e professor", expõe a contribuição para sua constituição profissional.

Pensando em construção do saber matemático, sabe-se que um ambiente favorável às relações, onde os alunos possam expressar-se sem ter medo de errar, é fundamental.

Percebe-se que se trata de um grupo muito harmonioso e que há cumplicidade entre os alunos e comprometimento por parte da professora, que se mostra sempre atenta ao andamento do aprendizado da classe como um todo. E pontualmente, quando necessário faz devolutiva às perguntas, mesmo que por vezes em um tom de voz alto $e$ desnecessário. Mas o interessante é que os alunos expressam suas idéias e são ouvidos pela professora. Outro aspecto que observei que define essa harmonia é que os alunos se ajudam, tanto em questões práticas como na falta de materiais, quanto para realização das atividades propostas pela professora.. (LARISSA).

Assim, é possível confirmar que a constituição da profissionalidade docente das alunas evidenciava-se nas narrativas e nas transformações que o curso e a participação do estágio favoreceram, pois, além das observações referentes à postura docente, à rotina da classe e às formas de apresentação e intervenção para favorecer aprendizagem de conteúdos de Matemática, existem também, nas narrativas algumas observações e reflexões sobre a classe, o entrosamento dos alunos e as posturas éticas (ou não) dos professores.

Nesse contexto, é possível afirmar que algumas narrativas evidenciam que as relações estabelecidas com os saberes, associadas à ocupação e à atuação dos professores (neste caso, das alunas estagiárias) no cotidiano escolar, influenciam significativamente no processo de profissionalização. Essas evidências, por vezes, propiciaram a ampliação dos saberes e dos conhecimentos do conteúdo pedagógico geral e dos conteúdos curriculares.

Ana Clara, por exemplo, na narrativa $\mathrm{n}^{\mathrm{o}} 2$, traz uma experiência que se refletiu na sua profissionalização, pois algo que considerava "fácil" se modificou após a análise da situação, do contexto e das intervenções. Ela percebeu que suas relações com os saberes sobre o conteúdo em evidência foram ressignificadas. A proposta consistia na escrita, pelos alunos, de números de 0 a 50 .

Muitas crianças se perderam, não conseguiam ver e registrar a sequência. $O$ caderno ficou todo sujo e feio de tanto os alunos apagarem, $e$ isso os deixou visivelmente frustrados. Depois de algum tempo a professora escreveu os numerais na lousa, para aqueles que ainda não haviam terminado copiar.

Um aluno em especial me chamou atenção, ele não conseguiu fazer os números: nem copiando ele não sabia a sequência. Quando ele começou a copiar, fez os números espelhados. Em nenhum momento houve intervenção da professora sobre esse aluno.

$$
[\ldots]
$$

No momento não achei a atividade significativa. Fiquei com a impressão de que eles não compreenderam a sequência dos números de 10 em 10 (a configuração do nosso sistema). Enfim, pensei que não sabiam por que tinham que escrever os números e, também, como fazer os registros. Depois entendi que é preciso propor os registros dos números para verificar se os alunos, ao registrarem $e$ recitarem os números, identificam seu valor numérico e posicional, além de avaliar quais alunos conseguem fazer os números na sequência, quais tem dificuldades e até onde conseguem registrar. A atividade foi demorada e considero que a professora deveria fazer intervenções durante a atividade para verificar as dúvidas $e$ incentivar os alunos que pararam de fazer, $e$ ainda mais, deveria se apoiar em diferentes formas de ensinar. (ANA CLARA, $1^{\circ}$ ano EF, narrativa n. 2, 30 abr. 2010)

Entende-se que a narrativa merecia alguns questionamentos. Assim, no encontro com a pesquisadora, o parecer de Ana Clara em relação à postura da professora: - "deveria se apoiar em diferentes formas de ensinar" - foi elemento de 
reflexão, diante da questão: o que fica implícito quando, como sujeito externo da situação, consideramos que existem outras formas de ensinar?

Uma das considerações do grupo referiu-se ao perfil dos alunos da classe e à postura da professora durante a realização da atividade. Prevaleceu, nesse momento, a questão de identificar se os alunos conhecem os números, se estão preparados para realização dos registros numa ordem numérica crescente e se sabem organizá-los no espaço e nas linhas do caderno, para que os registros estejam separados por traços para leitura. Também se discutiu a diferença entre recitar o número e escrever o numeral: por exemplo, o aluno, quando recita $20,21,22,23,24, \ldots$, identifica o número 2 como sendo vinte (duas dezenas) e os demais, como as unidades (quantidades individuais). Essa relação do número com a quantidade, com compreensão do valor posicional, poderia ser explorada. Na ocasião, outras duas alunas - Vivi e Larissa - deram como opção a colocação dos números em intervalos de dez em dez, ou seja de 0 a 10, de 11 a 20, de 21 a 30, [...] numa folha, para copiarem embaixo. Outra proposta foi da escrita dos números com intervalos em branco para colocação dos numerais que faltavam. Ou, ainda, propor a escrita de intervalos, por exemplo, de 13 a 23 , ou de 34 a 50, com orientações para os alunos que chegam ao 50 continuarem, dando a possibilidade de acompanhamento, pela professora, dos alunos com dificuldade para concluírem a sequência.

Assim, ficou evidente a necessidade de o professor estar atento a todos os alunos, dando diferentes oportunidades de construção de sequências numéricas com orientações. Essas considerações levaram o grupo a definir condutas docentes para o trabalho com os conteúdos e conceitos que envolvem o estudo do sistema de numeração decimal.

Tais reflexões e indagações sobre as respostas possíveis permitem às estagiárias a aproximação com o conhecimento do conteúdo pedagógico imbricado nos conhecimentos dos conteúdos da matéria a ser ensinada.

$\mathrm{Na}$ narrativa da pesquisadora sobre $\mathrm{o}$ encontro $\mathrm{n}^{\mathrm{o}} 3$, é possível verificar esses aspectos, bem como as opções de intervenções que o professor tem para que o aluno entenda e reconheça a regularidade do sistema de numeração decimal, naquele intervalo e/ou em outros.

Quanta informação sobre a escrita de numerais e a regularidade do sistema de numeração do sistema decimal! A narrativa da Ana Clara fez nosso encontro voar: o tempo ficou pequeno para tantas indagações sobre ensinar $e$ aprender numerais. A atividade proposta para alunos do $2^{o}$ ano parece ser tranquila: sabem recitar e, muitas vezes, não sabem registrar na ordem crescente, contudo para o aluno é trabalhosa e exige que conheçam a sequência e a regularidade numérica para realizarem os registros.

Explicita os números na ordem crescente, pareceu ser novidade, e o grupo anunciou não havia pensado nisso! A inclusão numérica, a sequência de $10 \mathrm{em} \mathrm{10,} \mathrm{a}$ verificação da posição numérica $e$ da diferença entre, por exemplo, 23 e 32, para o aluno que escreve espelhado também foram elementos de discussão. A aluna Rose comentou: "eu falo muito sobre este sistema decimal para meus alunos e não associava a questão do $10 \mathrm{em} 10 \mathrm{sem}$ ser 20-30 40, não havia pensado no 10 em 10 entre 1525-35”. (DENISE MARQUESIN, narrativa da pesquisadora, n. 4, 02 maio 2010).

Verifica-se que as reflexões do grupo relacionadas à função do professor como avaliador do que as crianças conhecem sobre o conceito de números, associadas às formas de intervenção para o entendimento das regularidades do sistema de numeração decimal, contribuíram para a constituição da profissionalidade docente. Gauthier (1998, p.71) justifica esta interpretação:

A profissionalidade se legitima e se remete à compreensão das imagens ou representações que o professor constrói a respeito do magistério, mesmo antes de ter começado a ensinar, já que a profissionalidade no ensino supõe assim uma mudança nos saberes e na integração na formação.

Aqui cabe um parêntese, pois as alunas normalmente consideram que a questão da afetividade e carinho por si só garante a aprendizagem; esse aspecto fez parte dos estudos realizados, e, de acordo com Nóvoa (2000), a educação escolar é feita por atividades educativas que envolvem a preparação, coordenação e avaliação das mesmas, com respeito à individualidade e ações centradas nos saberes 
subjacentes ao ato de ensinar, sem refração dos sentimentos e emoções.

Retornando às categorias da base de conhecimento anunciadas por Shulman (1987), a aluna Ana Clar refere-se não somente ao conhecimento pedagógico do conteúdo específico e ao conhecimento pedagógico geral, mas também ao conhecimento dos contextos educacionais, ao conhecimento dos fins, dos propósitos e dos valores educacionais, ao mencionar que é necessário ter foco na aprendizagem esperada.

Outras narrativas semelhantes à de Ana Clara mostraram que os conhecimentos profissionais relativos ao ofício docente envolvem o aprender a ensinar e a ser professor, atuando como professor: "ensinar exige um conhecimento do conteúdo a ser transmitido, visto que, evidentemente, não se pode ensinar algo cujo conteúdo não se domina" (GAUTHIER, 1998, p.29). A narrativa de Rose traz essa percepção:

No segundo dia de estágio, acompanhei a resolução de operações inversas e divisão. A professora relatou-me que havia necessidade em retomar o conteúdo desde a adição, pois alguns alunos não estavam acompanhando essas operações. Pude perceber que a professora precisa trabalhar os conteúdos propostos pela apostila, porém a dificuldade de se fazer uso da mesma, sem deixar "para trás" os alunos que ainda não têm definidos conceitos básicos da matemática, é um grande desafio.

Para driblar esse desafio, a professora retomou, passo a passo, fazendo intervenções a todo o momento, a fim de garantir o aprendizado. Auxiliei a professora no momento das intervenções, orientando os alunos a partir da maneira como a professora fazia e explicava na lousa e pontualmente, para os que mais precisavam de ajuda.

Pude perceber que, para ensinar matemática, além de ter o domínio do conteúdo, o professor precisa, ainda, saber como o aluno aprende, para usar uma linguagem que ele entenda. No caso desta classe, a professora D-2 faz isso muito bem, e eu espero aprender um pouco mais sobre a maneira adequada de exemplificar e explicar os conceitos matemáticos para os alunos.

Enfim, pude perceber que é necessário um bom entendimento do conteúdo, saber como a criança aprende $e$ quais os questionamentos que vão realmente ajudar aos alunos na construção de conceitos desse conteúdo. Nesse momento fui orientada pela professora, que ajudava com as perguntas aos alunos, para que o momento não fosse apenas de diversão para os alunos, mas para que contribuísse na construção de conceitos pelos alunos. (ROSE, narrativa $n .2,4^{\circ}$ ano, 24 mar. 2010).

As narrativas de Ana Clara e de Rose evidenciam que as apropriações dos conteúdos matemáticos adquiridos durante a escolaridade ou no curso de Pedagogia não foram suficientes para ensinar. Declaram que não estão preparadas para exercer a profissão, ou seja, expõem sua identidade e iniciam-se no processo de profissionalidade docente.

As reflexões das futuras professoras sobre a ação de ensinar e sobre os conhecimentos profissionais do conteúdo pedagógico geral, do currículo e dos alunos, que envolvem a ação de ensinar e sua apropriação, estão sendo conquistadas por sua experiência como estagiárias.

Esses aspectos esclarecem que a construção de conhecimentos profissionais resulta das relações estabelecidas com os saberes e com a reflexão sobre a experiência. Essas evidências ampliam-se quando se concebe que os conhecimentos profissionais são mais amplos que os saberes, exigem saberes contextualizados a respeito da escola, do programa de ensino, do conteúdo, da teoria e da ação pedagógica.

\section{Tecendo considerações}

A proposta de realização de estágio pelas alunas do curso de Pedagogia confirmou que, nos momentos de estágio do aluno da formação inicial, existem possibilidades de sair da condição de espectador do ensino para assumir as condições de docente quando existe reflexão, individual ou em grupo, sobre as responsabilidades, os desafios e os conflitos docentes, relacionados às vivências e às experiências com os rituais de ensino e, no caso deste artigo, sobre a aprendizagem de conteúdos matemáticos. Neste estudo de caso, as alunas do curso de Pedagogia anunciaram com naturalidade que os conteúdos de Matemática são "difíceis" de serem ensinados e que deve ser modificada a postura do professor que ainda adota a exposição do 
conteúdo, seguida de exercícios de aplicação e posterior correção, como procedimento para ensinar. As alunas têm como referência seu próprio processo de escolarização, as vivências como aprendizes numa escola de, no mínimo, dez anos atrás, com padrões de comportamento que privilegiam a avaliação pautada nos acertos e erros e/ou em crenças sobre a matemática como uma disciplina difícil de ser aprendida. Contudo, compreendem que os alunos do ensino fundamental, principalmente, precisam envolver-se com atividades de Matemática que ofereçam desafios, para levantar hipóteses, verificar os resultados e, de forma autônoma, desenvolver o pensamento matemático e o gosto pela disciplina. Elas, porém, não se sentem preparadas para essa tarefa. Afirmaram não gostar de Matemática e não saber ensiná-la, devido aos "traumas" e às marcas deixadas pelo processo de escolarização.

É importante enfatizar que, especificamente em relação ao ensino de conteúdos de Matemática, houve consenso, entre as estagiárias, de que, para construção de conceitos e apropriação de conteúdos afins, os alunos precisam comunicar suas ideias matemáticas, que serão valorizadas ou questionadas a partir das explicações e das validações e das conjecturas levantadas.

A observação do fazer docente e das vivências das estagiárias mostrou que, no início, buscavam participar de situações que garantissem aproximação com os conteúdos de matemática a partir da observação das aulas e do contexto de aprendizagem em evidência. No entanto, diante da criticidade de cada uma em relação à prática profissional docente, houve necessidade de ampliar esse foco mediante a compreensão de que a atividade docente extrapola os limites de sua sala de aula, pois o professor precisa ter conhecimento dos conceitos matemáticos, saber de que forma trabalhálos, criando ambientes favoráveis para a aprendizagem, além de ter disponíveis e saber utilizar os materiais e os recursos adequados. Essas percepções trouxeram para as alunas a confirmação da importância do trabalho pautado em resolução de desafios, a fim de possibilitar aos alunos interagir com os dados, levantar conjecturas, fazer aproximações e realizar os procedimentos adequados com segurança para encontrar as respostas. Outra confirmação refere-se, também, ao fato de que a análise das práticas relacionadas ao ensino de matemática para as séries iniciais colocou em questionamento o próprio conhecimento dos conteúdos matemáticos das estagiárias e seu futuro desempenho como professoras que ensinam matemática nas séries iniciais.

A adoção da produção de narrativas como instrumento de reflexão sobre a prática foi valiosa para as constatações acima: ao escrever, a aluna estagiária se torna agente ativo de sua própria compreensão, pois a escrita exige a vivência da atividade e a reflexão sobre as circunstâncias e os conhecimentos criados, testados, refutados $\mathrm{e}$ transformados.

Assim, este trabalho permitiu compreender que escrever é um dos movimentos de transformação da experiência em conhecimento, principalmente quando a produção da escrita está a serviço da identificação e da compreensão dos movimentos que interferem nas relações de ensino e de aprendizagem. Envolver-se com a escrita ajudou as participantes da pesquisa na exposição de um saber específico e particular, levando-as a reconhecerem-se como profissionais, ao aflorar o espírito crítico identificado em vários momentos da pesquisa.

\section{Notas}

1 "is a key factor in the process of teacher education and a prime opportunity for trainess to learn about the teaching profession" (SANMAMED; ABELEDO, 2011, p. 48).

2 Todas as narrativas trazem como referência, o nome da autoria em letra maiúscula, da letra $\mathrm{n}$, de um número e da data abreviada, representando o número e a data da narrativa produzida pela autora. È importante esclarecer que quando a narrativa se referir ao conteúdo ou episódio da sala de aula que a aluna participou, após o nome da autora aparecerá também o ano.

\section{Referências}

ANDRÉ, Marli Eliza Dalmazo Afonso de et al. Os saberes e o trabalho do professor formador num contexto de mudanças. In: ASSOCIAÇÃO NACIONAL DE PÓS-GRADUAÇÃO E PESQUISA EM EDUCAÇÃO - ANPED, 33., Caxambu. Anais. Caxambu, 2010.

BOURDONCLE, Raymond. La professionnalisation des enseignants: analyses sociologiques anglaises et américaines. Revue Française de Pédagogie, Paris, n. 94, jan./mar. 1991.

BRASIL. Decreto-Lei n.9394, de 20 de dezembro 
de 1996. Estabelece as diretrizes e bases da educação nacional. Diário Oficial da União, Brasília, seção 1, p. 27839, 23 dez. 1996.

COCHRAN-SMITH, Marilyn; LYTLE, Susan L. Relationships of Knowledge and Practice: teacher learning in communities. Review of Research in Education, USA, n. 24, p. 249-305, 1999.

CONNELLY, F. Michael; CLANDININ, D. Jean. Relatos de experiencia e investigación narrrativa. In: LARROSA, Jorge et al. Déjame que te cuente: ensayos sobre narrativa y educación. Barcelona: Editorial Laertes. 1995. p. 15-59.

GATTI, Bernardete A.; BARRETO, Elba S.Sá; ANDRÉ, Marli Políticas docentes no Brasil. Brasília:unesco, 2011.

GAUTHIER, Clermont. Por uma teoria da pedagogia: pesquisas contemporâneas sobre $\mathrm{o}$ saber docente. Ijuí, RS: Editora UNIJUÍ, 1998.

GOODSON, Ivor. Conhecimento e vida profissional: estudos sobre a educação e mudança. Porto: Porto Editora, 2008. p. 209-222.

GROENWALD, Claudia Lisete Oliveira; Cadernos Universitários: Estágio Supervisionado em Matemática I. Canoas: Editora ULBRA, 2005.

MIZUKAMI, Maria da Graça N. Aprendizagem da docência: algumas contribuições de L. S. Shulman. Educação - Revista do Centro de Educação da Universidade Federal de Santa Maria, Santa Maria, v. 29, n. 22, p. 8-22, 2004. Disponível em: <www.ufsm.br/ce/revista/2004>. Acesso em: maio 2010.

MONTERO, Lourdes. La construcción del conocimiento profesional del profesor Lisboa:
Instituto Piaget, 2001.

MOURA, Manoel Oriosvaldo. A atividade de ensino como ação formadora. In: CASTRO, Amélia Domingues; CARVALHO, Anna Maria Pessoa de (Org.). Ensinar a ensinar: Didática para a Escola Fundamental e Média. São Paulo: Pioneira; Thomson Learning, 2001. Cap. 8, p. 143-162.

PASSEGI, Maria da Conceição. Narrar é humano! Autobiografar é um processo civilizatório. In: PASSEGI Maria da Conceição; SILVA, Vivian Batista (Org.). Invenções de vida, compreensão de itinerários e alternativas de formação. São Paulo: Cultura Acadêmica, 2010. p. 103-130.

PIMENTA, Selma Garrido. Professor reflexivo: Construindo uma crítica. In: PIMENTA, Selma Garrido; GHEDIN, Evandro. Professor reflexivo no Brasil: gênese e crítica de um conceito. São Paulo: Papirus, 2001. p. 17-52.

PIMENTA, Selma Garrido; LIMA, Maria Socorro Lucena. Estágio e docência. São Paulo: Cortez, 2004.

SANMAMED, Mercedes; ABELEDO, Eduardo J. F. El practicum en el aprendizaje de la profesión docente. Revista Educación, n. 354, enero-abr., p. 47-70, 2011.

SILVA JÚNIOR, Celestino. Fortalecimento das políticas de valorização docente: proposição de novos formatos para cursos de Licenciatura para o estado da Bahia. Brasília: CAPES, UNESCO, 2010.

SHULMAN, Lee. Knowledge and teaching: Fundations of the new reform. Harvard Educational Review, v. 57, n. 1, p. 1-22, 1987.

\section{Sobre as autoras:}

Denise Filomena Bagne Marquesin: Doutora em Educação Matemática, PUC- SP. Pós-doutoramento em Educação pela USF. Atua como professora e Coordenadora de Licenciatura em Pedagogia da Faculdade Anhanguera de Jundiaí, SP.

Laurizete Ferragut Passos: Possui graduação em Pedagogia, mestrado em Educação pela Universidade Estadual de Campinas, doutorado em Educação pela Universidade de São Paulo e pós-doutorado pela Pontifícia Universidade Católica do Rio de Janeiro. Atua como professora da PUC São Paulo.

Artigo recebido em novembro de 2011.

Artigo aprovado em maio de 2015. 